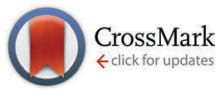

Cite this: Phys. Chem. Chem. Phys., 2016, 18, 1279

Received 17th September 2015, Accepted 20th November 2015

DOI: $10.1039 / c 5 c p 05577 f$

www.rsc.org/pccp

\section{The effect of iron re-deposition on the corrosion of impurity-containing magnesium}

\author{
Daniel Höche, ${ }^{\star a}$ Carsten Blawert, ${ }^{a}$ Sviatlana V. Lamaka, ${ }^{a}$ Nico Scharnagl, ${ }^{a}$ \\ Chamini Mendis $^{a}$ and Mikhail L. Zheludkevich ${ }^{\mathrm{ab}}$
}

\begin{abstract}
This article provides a contribution towards the mechanistic understanding of surface phenomena observed during the corrosion of $\mathrm{Mg}$-based substrates particularly in the low anodic polarization range. The concept considers the recent literature explaining cathodic hydrogen evolution from noble acting areas even during global anodic polarization. Heavy metal impurities in the ppm range or intermetallics are always present even in highly pure magnesium. Their potential effect was investigated here in more detail. The experimental results contribute to understanding the role of iron impurities in dark area formation and suggest a way for linking the observed phenomena to the recent literature. The shown enhanced cathodic activity of dark areas especially at the corrosion front and the superfluous hydrogen are linked to an iron re-deposition mechanism due to iron reduction. The proposed mechanism is based on the results obtained from innovative characterisation techniques using magnetic fields, diffraction experiments and transmission electron microscopy, which show the formation of iron rich zones, especially at the corrosion front offering "in statu nascendi" metallic Fe films acting as active cathodes for hydrogen reduction.
\end{abstract}

\section{Introduction}

The special behaviour of magnesium during anodic polarization is widely known and has been the subject of various scientific investigations. ${ }^{1,2}$ The strong hydrogen evolution reaction (HER) cannot be explained by the standard theory of anodic dissolution of metals. Already in the $1920 \mathrm{~s}^{3}$ the phenomenon was known and also more than 30 years ago ${ }^{4-6}$ the issue was already of great interest. Recent discussions between Atrens, Kirkland and Birbilis $^{7-9}$ reveal fundamental differences in the opinions on the reason for the explanation of the general Negative Difference Effect (NDE) mechanism. The NDE was also shown for aluminium alloys $^{10,11}$ especially for $\mathrm{Cu}$ rich alloys containing the S-phase. Drazic et al. ${ }^{12}$ stated a direct relation to pitting driven dissolution mechanism. It is also generally known that the effect is stronger for less noble metallic alloys assuming comparable electrolyte exposure conditions. All these facts indicate that there can be a general mechanism behind the NDE.

Several recently published studies try to explain the observed effects. ${ }^{13-16}$ Summaries can be found in the publications of Curioni et al., ${ }^{17}$ Bender et al., ${ }^{18}$ Atrens et al. ${ }^{19}$ or the very detailed work of Frankel et al. ${ }^{20}$ Williams, Frankel, Samaniego

\footnotetext{
${ }^{a}$ MagIC - Magnesium Innovation Centre, Helmholtz-Zentrum Geesthacht, Max-Planck Str. 1, 21502 Geesthacht, Germany.E-mail: Daniel.hoeche@hzg.de

${ }^{b}$ Department of Materials and Ceramic Engineering/CICECO, University of Aviero, 3810-193 Aveiro, Portugal
}

and Birbilis gave a strong feedback to the cathodic activity increase during anodic polarisation. ${ }^{1,7,21}$ Williams et al. ${ }^{1}$ have shown that there are persistent cathodes on the anodically polarized $\mathrm{Mg}$ surface. This indicates that superfluous hydrogen comes from a cathodic reaction which occurs at more noble inclusions present on an $\mathrm{Mg}$ surface. Birbilis et al. ${ }^{22}$ have also shown the enhanced catalytic response by measuring enhanced cathodic currents, and even the net polarity reversal of $\mathrm{Mg}$ surfaces held at an anodic potential. It is pointed out that the sites on the Mg surface enriched with noble metals (with higher exchange current density for hydrogen reduction, such as $\mathrm{Cu}$, $\mathrm{Al}, \mathrm{Ni}, \mathrm{Zn}, \mathrm{Fe}$, and $\mathrm{Mn}$ ) provide more favourable places for the cathodic reaction. Identifying the source of evolving hydrogen these studies do not clearly explain and validate how such an extensive amount of hydrogen can be cathodically generated on the noble inclusions, since they constitute only a minor fraction of the total surface area of the Mg-based substrates. In particular it is true for magnesium of relatively high purity where the concentration of impurities is at the ppm level.

Recent publication by Lebouil et al. ${ }^{23}$ promotes the so-called "filming" model. It is a description starting from initial impurity related reactions towards film formation (dark region of the $\mathrm{Mg}(\mathrm{OH})_{2} / \mathrm{MgO}$ bilayer $)$ and its spatial extension. According to the model hydrogen gas is formed via persistent cathodic reaction on the bilayer. Thus, the NDE is not driven by anodic dissolution as also explained in the review of Thomas et al. ${ }^{24}$ The main question remaining is how this oxide/hydroxide layer 
which is not electronically conductive ${ }^{25}$ (it possesses only ionic conductivity) can act as an efficient cathode?

Thomas et $a .^{24}$ stated that besides the mentioned filming effect impurities influence the HER: “. . .other metals may serve as preferred sites for high rates of HER, whilst their presence in the film could catalyse the HER, increasing the overall rate of the reaction forming $\mathrm{Mg}(\mathrm{OH})_{2}$ ". This indicates a direct linking to the impurities. However the presence of such metallic inclusions within the oxide-hydroxide layer electrically decoupled from the $\mathrm{Mg}$ matrix should not contribute to the cathodic processes because of the negligible electron conductivity of oxides.

Fajardo et $a .^{26}$ carried out galvanostatic experiments showing enhanced cathodic activity on ultra-highly pure $\mathrm{Mg}$ - UHP (0.1 ppm Fe measured using a spark source mass spectrometer). The surface appearance of low impurity level samples was surprisingly strongly affected after the tests, although they use $0.1 \mathrm{M} \mathrm{NaCl}$ test solution. The explanation is rather difficult since the cathodic reaction has to occur on $\alpha-\mathrm{Mg}$. It is commonly known that the Tafel reaction of $\mathrm{H}_{2}$ generation can occur on bare $\mathrm{Mg}$. According to the theory for a Tafel-driven HER, two adsorbed protons $\left(\mathrm{H}_{\mathrm{ad}}\right)$ are required. They have to arise via electrochemical adsorption (Volmer step) which for UHP Mg means:

$$
\mathrm{Mg}+\mathrm{H}_{2} \mathrm{O}+\mathrm{e}^{-} \rightarrow \mathrm{Mg}-\mathrm{H}_{\mathrm{ad}}+\mathrm{OH}^{-}
$$

As a consequence this implies that the HER depends on the amount of $\mathrm{H}_{\mathrm{ad}}$ (adsorbed protons). Their amount depends on available electrons. If the system is globally polarized anodically a large number of electrons are generated which are consumed by HER ( electrons is related to the very strong driving force for $\mathrm{Mg}$ oxidation. Thus, despite a certain polarisation resistance due to HER, the potential is driven so far negative of the equilibrium potential for proton reduction and the electron generation rate remains exceedingly high. As a result, there are sufficient electrons that can interact immediately. Such materials behaviour occurs if it is non-polarizable. As a result, the increase of anodic polarization and the increase of anodic reactions accelerate $\mathrm{H}_{\mathrm{ad}}$ formation. This chemisorption on $\mathrm{Mg}$ is well known and was shown by Bird et al. ${ }^{27}$

However, chemical desorption via Tafel is "slow". Thus the current increase is limited. The only possibility to get an increase of HER as measured must be a very fast process like electrochemical desorption. It is well known that this process (Heyrovsky) occurs as a rate determining step on 3d transition metals $\left(\mathrm{Fe}, \mathrm{Ni}\right.$, and $\mathrm{Cu}$ ) or even $\mathrm{Pt}$ as a pure transfer reaction. ${ }^{28}$ And it is also known that Heyrovsky reaction is the preferred mechanism in an alkaline environment. That is one reason why they are used for hydrogen production. It is very interesting that those conditions occur on $\mathrm{Mg}$ during corrosion.

The studies of Norskov et al. ${ }^{29}$ and Bird et al. ${ }^{27}$ of $\mathrm{H}_{2}$ on $\mathrm{Mg}(0001)$ showed the chemisorbed stage of $\mathrm{H}_{\mathrm{ad}}$ on the surface. In this context we would like to refer to the study of Vegge et $a l^{30}$ as well. The logical conclusion is that the Tafel process drives hydrogen formation reaction in the $\mathrm{Mg}$ primary phase.

It was shown by Pozzo et al. ${ }^{31}$ that transition metal dopants in magnesium can modify the catalytic activity. Their efficiency can be described via the Volcano plot with $\mathrm{Ni}, \mathrm{Fe}$ and $\mathrm{Rh}$ sitting near the top of the volcano. As a consequence, the HER (Tafel-like) during anodic polarization of $\mathrm{Mg}$ could even increase at the $0.1 \mathrm{ppm}$ Fe impurity level.

The occurrence of enhanced cathodic activity after cyclic polarization observed by Fajardo et al. ${ }^{26}$ seems to be related to a roughening effect since the strength of increase is limited. This does not exclude that dopants from $\mathrm{Fe}$ and $\mathrm{Ni}(0.1 \mathrm{ppm}$ is sufficient) complement the catalytic properties of $\mathrm{Mg}$ leading to enhanced hydrogen kinetics. For high impurity levels a convolution of the mentioned effects and the major cathodic reactions on impurities drive the HER. This would also explain why the "strength of increase" increases with the impurity level until saturation due to the surface morphology and the electrolyte as observed in ref. 22 and 26.

The experiments of Curioni et al. ${ }^{32}$ showed that the highest current occurs close to the corrosion forefront. They also measured a decreasing cathodic current contribution of the dark film with increasing distance which contradicts to Fajardo's statement. Recent SVET studies by Williams et al. ${ }^{33}$ show the circular expansion of the mentioned dark area confirming the occurrence of the highest dissolution at the interface to unaffected magnesium and they clearly show cathodic current contribution over the entire dark film slightly decreasing with distance to the interface. This can be partially related to the ongoing densification of precipitated hydroxide on top of the dark zone. Brady et $a l^{34}$ and their results measured by neutron scattering strongly support this aspect since they show a densification down to $40 \%$ nanoporosity. This value fits to modelling assumptions of Höche ${ }^{35}$ and to studies of Deslouis et al. ${ }^{36}$ Hydroxide formation itself is also related to $\mathrm{pH}$ conditions. Rossrucker et $a l^{37}$ studied the $\mathrm{pH}$ dependence and showed increased HER with decreasing $\mathrm{pH}$ which is also related to the mentioned precipitation kinetics and densification.

Despite all differences the impurity effect remains. The occurrence of transition metal elements like iron on the corroded surface was shown by Cain et al. ${ }^{38}$ Also the latest results of Yang et al. ${ }^{39}$ clearly support the iron impact on HER. A possible morphology of the active zone is shown by Lynse et $a l^{40}$ Interesting contribution was given by Salleh et al. ${ }^{41}$ Their results state that iron particles entrapped under corrosion products still can sustain HER at high rates which fits to the previously mentioned results and is in line with those of Brady et $a l^{34}$ More important is the following statement of Salleh et al.: "E1 "Enhanced HER on Mg is an effect of the enhanced water self-dissociation upon magnesium, attributed to the presence/growth of the $\mathrm{Mg}(\mathrm{OH})_{2}$ layer on its surface", considering the findings of Williams et al. ${ }^{42}$ by density functional theory - DFT calculations. These results suggest that water reduction can occur on $\mathrm{Mg}(\mathrm{OH})_{2}$, but do not explain where the required electrons come from. Deslouis et $a l^{36}$ and especially Nelson et $a .^{25}$ clearly showed the dielectric nature of $\mathrm{Mg}$ hydroxide which contradicts to this approach. Nevertheless, the question remains open: can contribution of this effect be stronger than the electrochemical driven water reduction especially on $3 \mathrm{~d}$ transition metals at strongly negative potentials? 
Discrepancies in dark area contribution strength can be explained by the different electrolyte used by the authors affecting the potential (electric) field distribution. This effect is clearly validated by Williams et al. ${ }^{33}$

Based on the results achieved by experiments with ferrofluids, by TEM studies and by grazing incidence X-ray diffraction (GIXRD), we suggest a mechanism of extensive hydrogen evolution related to re-deposited metallic Fe film at the corrosion forefront and subsequent cathodic Heyrovsky reaction of water reduction. Such reactions can occur at much higher rates than the one going via the conventional Volmer-Tafel route for hydrogen evolution. As a result, the extensive HER is a superposition of interacting effects whereas the impact of cathodic reactions on dark areas changes with corrosion duration depending on the local conductivity and the $\mathrm{pH}$ value. The cathodic performance of the dark film will be explained by the deposition of metallic films on the very surface as a result of reduction of iron oxides to Fe as shown by Le et al., ${ }^{43}$ respectively. Armstrong et $a .^{44}$ demonstrated an ongoing hydroxide precipitation on top as previously introduced by other authors.

The obstacles of experimental access to the in situ process occurring during dark film formation are well known. ${ }^{38,45}$ Thus, the validation of the surface morphology requires an unusual and innovative use of methods. Two promising candidates are magnetic domain visualisation according to the Bitter decoration method ${ }^{46}$ and in situ diffraction experiments ${ }^{47}$ allowing in situ phase formation studies during potentiodynamic polarisation. Apart from that, very interesting information can be received using Mössbauer spectroscopy. ${ }^{48}$

\section{Experimental}

\subsection{Electrochemical tests}

For complementary experiments different species of magnesium 99.98\% (ppm: Fe-47, Ni-2, Cu-5), 99.95\% (ppm: Fe-179, Ni-2, Cu-2), 99.95\% (ppm: Fe-220, Ni-2, Cu-5) and 99.94\% (ppm: Fe-65, Ni-2, $\mathrm{Cu}-3)$ were used. Bare materials were cut into pieces, ground, polished and rinsed with ethanol. Polishing was performed on a slow rotating disc via diamond paste (1 $\mu \mathrm{m}$ particles). For subsequent cleaning and rinsing a soft alkaline cleaning solution was used. Potentiodynamic cathodic polarization (sweep rate of $30 \mathrm{mV} \mathrm{min}{ }^{-1}$ ) was performed in stirred $0.5 \mathrm{wt} \% \mathrm{NaCl}$ solution at a $\mathrm{pH}$ value of 10.5 for the impurity elements to match typical conditions at the very surface during magnesium corrosion.

The corrosion cell $(333 \mathrm{ml})$ with a three electrode set-up consisted of an $\mathrm{Ag} / \mathrm{AgCl}$ reference electrode, a $\mathrm{Pt}$ counter electrode and the specimen itself $\left(1.54 \mathrm{~cm}^{2}\right)$ as a working electrode. The electrolyte temperature was $21.5 \pm 0.5{ }^{\circ} \mathrm{C}$ and the electrolyte being in equilibrium with the atmosphere was stirred during the potentiodynamic polarization measurements.

\subsection{Hydrogen evolution}

Additionally, for HER investigations on Mg- $x$ ppm Fe $(x=47,65$, 179) an initial pH of 7 was used in a very slow stirred aqueous 5 wt $\% \mathrm{NaCl}$ solution to accelerate $\mathrm{H}_{2}$ generation. HER was measured for different anodic potentiostatic polarization conditions without IR compensation by a modified test cell $\left(\mathrm{WE}-1.54 \mathrm{~cm}^{2}\right)$ connected to a hydrogen collecting burette. To minimize the loss of $\mathrm{H}_{2}$ due to adsorption at the cell wall the setup was initially flushed with hydrogen gas in order to minimize adhesion effects (secondary bubbles).

\subsection{Iron deposition simulation}

In order to validate and to simulate the Fe impact on the enhanced catalytic activity magnesium 99.98\% (47-ppm Fe) has been treated in iron containing salt solutions. The treatment was performed at open circuit potential in $0.5 \mathrm{M} \mathrm{FeCl}_{2}$ for $5 \mathrm{~min}$ and $30 \mathrm{~min}$ at $\mathrm{pH} 7$ or 10.5 . Immediately after the process the samples have been cathodically polarized as previously explained in Section 2.1, in order to study the corresponding hydrogen evolution rate.

\subsection{X-ray photoelectron spectroscopy (XPS)}

X-ray photoelectron spectroscopy (XPS) experiments were carried out using a Kratos Axis Ultra DLD system working with a $15 \mathrm{kV}$ X-ray gun using monochromatic Al-K $\alpha$ radiation. The analyzed area size was set to $700 \mu \mathrm{m} \times 300 \mu \mathrm{m}$ and the pass energy was set to $40 \mathrm{eV}$ for the region scan.

\subsection{Transmission electron microscopy (TEM)}

The specimen (corroded Mg-65 ppm Fe) for TEM investigation was prepared from regions adjacent to the dark zone area using focused ion beam (FIB) milling using a FEI Helios NanoLab 600 DualBeam FIB/SEM. The specimen surface was protected with a $300 \mathrm{~nm}$ Pt layer prior to FIB processing with Ga+ ions to protect the specimen from damage. The TEM samples were mounted on $\mathrm{Cu}$ grids for TEM investigations. Transmission electron microscopy was performed on a FEI CM200 Transmission electron microscope equipped with an EDAX energy dispersive X-ray (EDS) spectrometer operating at $200 \mathrm{kV}$.

\subsection{Magnetic field influenced corrosion and imaging by the Bitter decoration method}

A water based ferrofluid containing up to $4 \%$ (Vol.) magnetite nanoparticles (av. $d=30 \mathrm{~nm}$ (EMG 705, FerroTec)) was used to visualize the arising magnetic structure using the Bitter decoration method. ${ }^{46}$ Dark area formation was studied on the Mg-220 ppm Fe sample sheet positioned on a strong neodymium-iron-boron magnet. The magnetic field interacts with the re-deposited iron by inducing a dipole moment, respectively, and magnetization which subsequently interacts with the ferrofluid. A drop of $0.5 \mathrm{wt} \% \mathrm{NaCl}$ solution was placed on top of the $\mathrm{Mg}$ sample and the setup was placed under an optical microscope to observe the progress of dark area formation. After the corrosion front (dark area) was formed the ferrofluid was added to the drop of $\mathrm{NaCl}$ solution using a pipette $(2 \mu \mathrm{l})$. During the procedure the $\mathrm{Mg}$ sample remained on the magnet. Since micro-convection within the droplet can influence the results, the whole setup was not moved afterwards. After the ferrofluid particles positioned themselves due to magnetic forces on the corroded $\mathrm{Mg}$ surface, the samples were rinsed with ethanol, dried at $60{ }^{\circ} \mathrm{C}$ and studied 
using SEM and EDX mapping and compared with a reference sample that is not positioned on the magnet. 22 corrosively active dark area spots were analysed: 15 tests on the neodymiumiron-boron magnet and 7 tests without placing the $\mathrm{Mg}$ sample in the strong magnetic field.

In order to validate iron deposition, the corrosion conditions were simulated by the immersion of $\mathrm{Mg}$ test samples into iron salt containing solutions (as described in Section 2.3). The Bitter test has been repeated on a sample ( $\mathrm{Mg}-47 \mathrm{ppm} \mathrm{Fe}$ ) after $1 \mathrm{~min}$ in $0.5 \mathrm{wt} \% \mathrm{NaCl}+0.05 \mathrm{M} \mathrm{FeCl}_{2}$ solution at $-1.2 \mathrm{~V} v s$. OCP potentiostatic conditions. This cathodic potentiostatic treatment and the related hydrogen evolution are required to induce reduction reaction of iron-rich phases to metallic Fe. The used parameters were derived from the studies of Flis-Kabulska et al.,$^{43,44,49}$ Zou et al..$^{50}$ Allenore et al. ${ }^{51,52}$ and Beverskog et al. ${ }^{53}$ For example Flis-Kabulska et al. ${ }^{49}$ showed reduction reactions and electrode activation due to Fe deposition at a cathodic overpotential of about $-1.09 \mathrm{~V} v$ s. $\mathrm{Hg} / \mathrm{HgO}$ in an alkaline electrolyte. A more detailed description will follow in Section 4.2.

\subsection{Grazing incidence X-ray diffraction (GIXRD)}

Samples for GIXRD analysis were prepared as previously described in Section 2.1 by anodic polarization for 30 minutes. During the formation of the dark zone the samples were positioned (focus alignment) and analysed under exposed conditions. Measurements were performed on a Bruker D8 Advance (DaVinci design) equipped with a eulerian cradle and in grazing incidence geometry (Göbel mirror, $2^{\circ}$ sollers, LynxEye detector-0D) at different incident angles to record depth information (4s counting time per step). Angles have been varied stepwise between $0.15^{\circ}$ and $0.9^{\circ}$. Data analysis was carried out using common analysis software (BrukerEVA and PDF + 4 2014).

\section{Results}

\subsection{Potentiodynamic polarization and hydrogen evolution}

Fig. 1 presents the cathodic polarization curves obtained on $\mathrm{Mg}$ samples with different amounts of Fe impurities. The measurements were performed after different times of $100 \mathrm{mV}$ potentiostatic anodic polarization. It can be clearly seen that the increased level of Fe leads to higher cathodic currents because of more intensive hydrogen evolution on inclusions. However another important effect is also observed. The cathodic activity for the same type of $\mathrm{Mg}$ is increasing with time of anodic polarization. This effect can be related to the increase of effective cathode area during anodic polarization. The increase of cathodic active area during corrosion due to the enrichment of impurities was already shown in the literature. ${ }^{16,22,26}$ The measured potential is shifted towards the noble side due to increasing Fe containing areas related to the uncovered impurities and the proposed film deposition effect (any other noble compounds can interact as well). Continuously, the present surface conditions (surface fraction ratio of cathode $(\mathrm{Fe}) v s$. anode $(\mathrm{Mg})$ ) change and a mixed potential occurs which is still

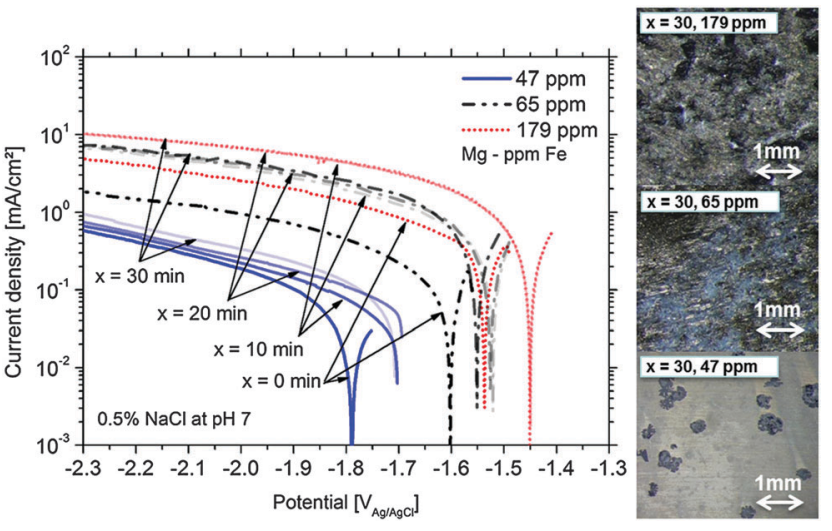

Fig. 1 Enhanced cathodic activity after anodic potentiostatic polarization for $x=0,10,20,30$ minutes at $+100 \mathrm{mV}$ vs. OCP for pure Mg containing different Fe levels and their surface appearance after $x=30 \mathrm{~min}$ (initially all had a shiny surface).

cathodic to the impurity elements and close to the magnesium OCP. The achieved corrosion kinetics is determined by the impurity content and by the number of iron-rich particles getting detached from the substrate due to anodic polarization, as it will be described in Section 4. Furthermore, the maximum cathodic current is also dependent on the iron content. Fig. 1 clearly validates the direct correlation between the dark film area and the Fe content.

The maximum of cathodic current was measured even after $10 \mathrm{~min}$ at $+100 \mathrm{mV} v \mathrm{~s}$. OCP of the $179 \mathrm{ppm}$ Fe sample (sample surface was fully dark). According to the observations the maximum is determined by the rough "dark" area and the IR (ohmic) properties of the electrolyte.

For further verification, some hydrogen evolution rate tests were performed for magnesium samples with different impurity levels (Fig. 2). At low (uncorrected) anodic polarization the HER increases with the amount of impurities. A further increase to a certain amount of anodic polarization leads to a smaller increase of HER since IR-effects become relevant.

As shown in Fig. 2, especially for the 179 ppm Fe sample, the HER without external polarization is at a high level. This is related to the self-accelerating corrosion process due to the interaction of impurities, HER and the proposed re-deposition. Dissolution of $\mathrm{Mg}$ leads to uncovering of impurities at the surface making them more accessible for contact with the electrolyte. This mechanism contributes to the increased effective surface area of the cathodic sites leading to the increase in the HER rate and was recently suggested by Taheri et al. ${ }^{16}$

However, the large amount of hydrogen cannot be explained by impurities alone. One of the possible explanations is redeposition of iron from dissolved iron rich impurities detached from the corroding matrix by a mechanism, which has been validated for aluminum alloy 2024 when copper is re-deposited on the aluminum surface around S-phase intermetallics (73). In the case of Fe re-deposition as a thin film, a large cathode can be formed from relatively small dissolved iron precipitates drastically increasing the surface area available for HER. This would also explain the unproportional difference between the 


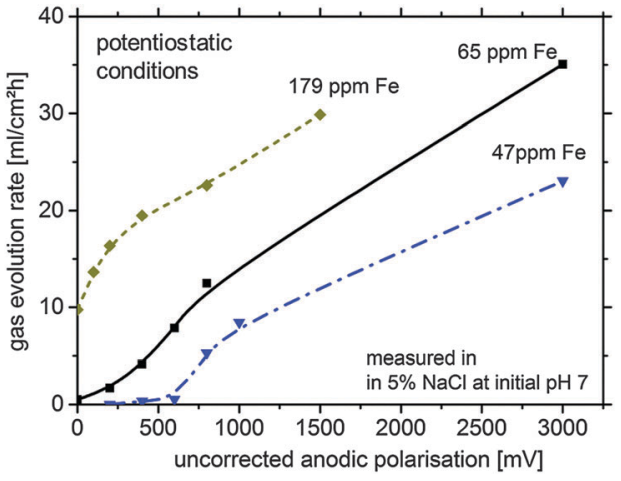

Fig. 2 Typical hydrogen gas evolution rate under various potentiostatic conditions (not IR-corrected) for different magnesium systems in $5 \mathrm{wt} \%$ sodium chloride solution (lines are just for better visualisation; error $>10 \%$ ). The duration of hydrogen collection per point was $12 \mathrm{~min}$ for 179 ppm Fe, 30 min for 65 ppm Fe and 60 min for 47 ppm Fe.

measured HER of Fig. 2 (factor of approx. 10-100) and the impurity content (factor of approx. four). The sources of Fe ions in the solution are the small iron containing impurity particles freed from the $\mathrm{Mg}$ matrix in the course of dissolution. The free sub-micron scale iron rich particles, losing galvanic protection after the electrical contact with the matrix is lost, can be dissolved because of free corrosion in the aggressive electrolyte. They generate iron cations, and due to local conditions at the corrosion front, subsequent re-deposition takes place. This effect will be described in more detail in Section 4 .

If this knowledge is taken into consideration, the whole hydrogen generation process has two major sources:

(1) Continuing water reduction at the existing particles of impurities partially embedded in the $\mathrm{Mg}$ matrix

(2) HER at growing areas of metallic re-deposited iron at the corrosion forefront (dark area growth).

The following part of this manuscript is focused on providing experimental evidence for the iron re-deposition process during $\mathrm{Mg}$ corrosion.

\subsection{Magnesium - dark film simulation}

At first, the experiments were carried out in order to show that the addition of $\mathrm{Fe}$ (II) to the electrolyte can increase the cathodic activity. The suggestion is that $\mathrm{Fe}^{2+}$ from solution can be reduced on the $\mathrm{Mg}$ surface to form metallic Fe film which will act as a large cathode. As shown in Fig. 3 for $\mathrm{Mg}$ immersed in different iron salt containing solutions $\left(0.5 \mathrm{M} \mathrm{FeCl}_{2}\right.$ at $\mathrm{pHs}$ 7 and 10.5 for $5 \mathrm{~min}$ and $30 \mathrm{~min}$, respectively), an enhanced cathodic activity is observed when $\mathrm{Fe}$ (II) is present in the solution. The observed cathodic activity is similar to the measured activity of magnesium with 65 ppm Fe after dark area formation as shown in Fig. 3 as well. This increase of activity provides an additional contribution to the idea of formation of metallic $\mathrm{Fe}$ deposits on the magnesium surface creating additional sides for enhanced cathodic activity.

The validation of metallic film formation during $\mathrm{Mg}$ corrosion in an aqueous environment is not a trivial task, especially from the point of view of experimental access to in situ conditions. X-ray

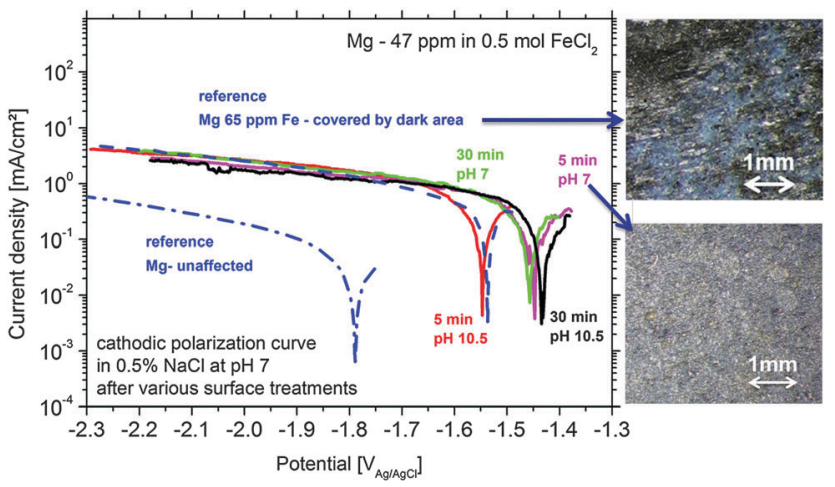

Fig. 3 Increased cathodic activity of Mg-47 ppm Fe samples after immersion treatments in $0.5 \mathrm{M} \mathrm{FeCl}_{2}$ solution for 5 and $30 \mathrm{~min}$ at $\mathrm{pH} 7$ and 10.5. For comparison the initial bare- and corroded Mg- 65 ppm Fe with the fully corroded surface are shown. The dark surface appearance of two test samples is shown by optical micrographs (initially all had a shiny surface).

photoelectron spectroscopy (XPS) was used here to obtain information about the chemical state at the very surface (first 5-10 nm) of corroded $\mathrm{Mg}$ samples. However the samples have to be dried before the measurement since the method requires high vacuum. As a consequence the samples were immediately dried after the tests in order to stop all electrochemical processes as fast as possible. Measurements on the $\mathrm{Mg}-179 \mathrm{ppm} \mathrm{Fe}$ sample do not reveal any iron peak due to the detection limit $\left(\sim 10^{-3}\right.$ to $10^{-2}$ at $\left.\%{ }^{54}\right)$ and even more important, the continuing $\mathrm{Mg}(\mathrm{OH})_{2}$ formation after removing the electrolyte. Thus, the XPS study was also performed on a specimen after being immersed in the iron chloride solution and after cathodic polarization according to Fig. 3. As illustrated in Fig. 4, the signal of iron $2 \mathrm{p}^{3 / 2}$ of this test sample contains multiple excitations.

According to the literature ${ }^{55-57}$ multiple peak-fitting of Fe compounds is critical due to convoluted signals related to spin-orbit coupling with unpaired $3 \mathrm{~d}$ electrons and electrostatic interaction. The evaluation, as shown by Grosvenor et al. ${ }^{57}$ applying the Shirley background, matches very well and therefore was used in first approximation. The presence of $\mathrm{Fe}_{2} \mathrm{O}_{3}$ and $\mathrm{FeOOH}$ was detected, however without distinguishing between $\alpha$ and $\gamma$ modification. The physical meaning of the pre- and surface peak in Fig. 4 is explained in Grosvenor's work as well. $\mathrm{Fe}^{2+}$ signals are contributed to remaining iron chloride and other oxides. Metallic Fe (expected at $706.6 \mathrm{eV}$, ref. 56) could not be detected in this case because of the very fast oxidation of the thin Fe film after terminating immersion. Thus, much experimental effort (especially in situ) is required to prove that metallic $\mathrm{Fe}$ is formed at the corrosion front.

\subsection{TEM studies}

The observed effects are related to phenomena occurring at a nanometer scale. Via TEM studies shown in Fig. 5 it was possible to take a cross-sectional micrograph (screenshot) of the re-deposition situation at the corrosion front. Since measurements were performed under dry (vacuum) conditions $\mathrm{MgO}$ was observed on top instead of $\mathrm{Mg}(\mathrm{OH})_{2}$. This is related to the dehydration/decomposition of the nanocrystalline $\mathrm{Mg}(\mathrm{OH})_{2}$ 


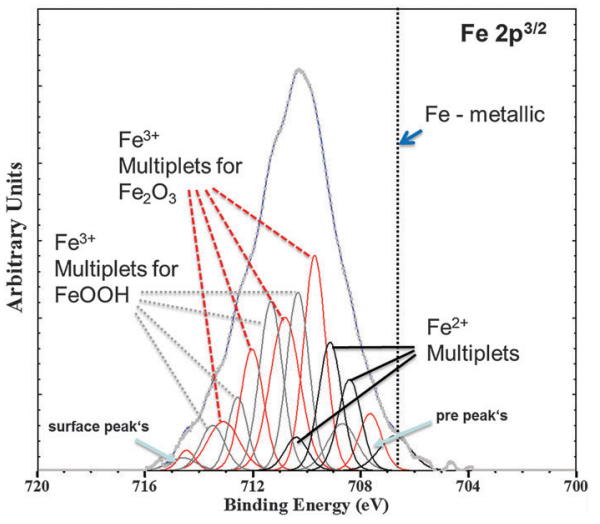

Fig. $4 \mathrm{Fe} 2 \mathrm{p}^{3 / 2}$ XPS spectra (Shirley background corrected) of the Mg-47 ppm Fe sample after immersion in 0.5 molar $\mathrm{FeCl}_{2}$ solution for 5 min at initial $\mathrm{pH} 7$ validated deposition of the Fe rich phase. Multiplet fitting according to the study of Grosvenor et al. ${ }^{57}$ is implemented as well. Differentiation between $\alpha$ and $\gamma$ modifications of $\mathrm{Fe}_{2} \mathrm{O}_{3}$ and $\mathrm{FeOOH}$, respectively, is not indicated.

forming $\mathrm{MgO}^{58-60}$ on the corroded sample under dry conditions (like in a vacuum).

Fig. 5a shows a typical Fe rich particle $(\sim 80 \mathrm{~nm}$ diameter $)$ containing Si and Mn related to the metallurgical history of the sample. It has a ferrite crystalline structure and is fully embedded. Fig. $5 \mathrm{~b}$ delivers clear indication for the re-deposition mechanism. At the foremost position of the corrosion front the EDS analysis showed a significant iron signal whereas $\mathrm{Si}$ and $\mathrm{Mn}$ (as it should be for particles) did not occur (Si very weak). Thus, the detected iron originates from re-deposition rather than iron-rich particles. Additionally, the position is close to voids in an area with previously removed particles due to corrosion related detachment from the matrix. It cannot be directly proven that one of the particles was detached but, since the EDS shows iron as introduced by the re-reposition mechanism, it is most probable. The fact that, at a similar interface position between $\mathrm{MgO}$ and $\alpha$-Mg without involved iron-rich particles, no EDS, Fe signal occurs, once again affirming the proposed mechanism.

\subsection{Magnetic domains}

Since ferromagnetic iron is involved, there should be an interaction of an external magnetic field (neodymium-ironboron magnet) with the dark area. Consequently, the induced magnetization alters the magnetic properties. It is also known that iron oxides (excluding FeO), ${ }^{61}$ oxy-hydrides and hydroxides ${ }^{62-64}$ behave as ferromagnetic materials. Due to the interaction of the dipole moments of iron and iron-rich phases with the external magnetic field, the coverage by nano-magnets of water-based ferrofluid should be influenced. The alignment according to the magnet field vector $\overrightarrow{\mathbf{B}}$ allows correlation with iron distribution. After optimization of solution compositions, droplet sizes, magnet positions, and minimization of ferrofluid agglomeration, several tests were performed and compared.

Fig. 6 shows the SEM images and corresponding $\mathrm{Mg}$, $\mathrm{O}$ and $\mathrm{Fe}$ - EDS elemental mapping obtained after short exposure of $\mathrm{Mg}(220 \mathrm{ppm} \mathrm{Fe})$ to a drop of $0.5 \mathrm{wt} \% \mathrm{NaCl}$ solution. The shape a)

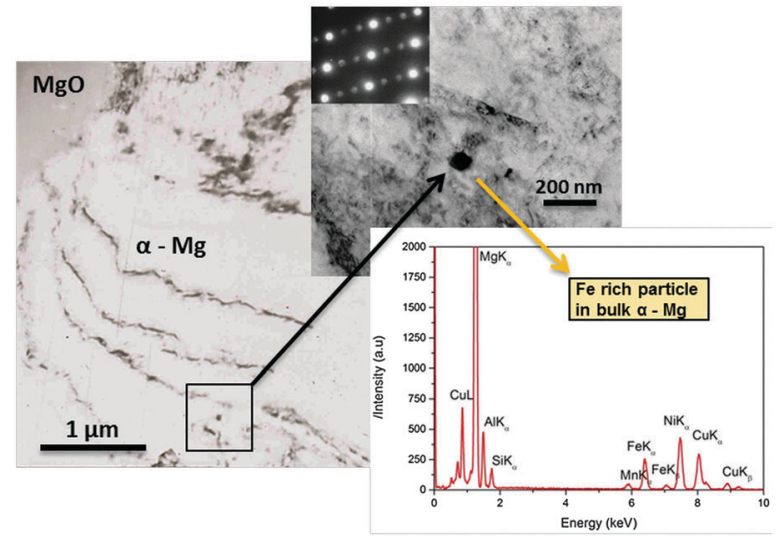

b)

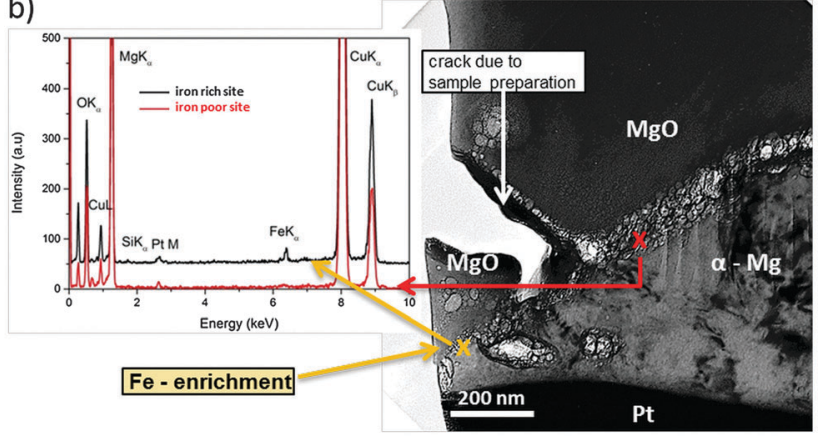

Fig. 5 TEM micrographs on a cross-section of corroded (dark area zone) Mg-65 ppm Fe. (a) Fe-rich particle containing Si and Mn embedded into magnesium. Iron diffraction pattern indicates a ferrite structure. (b) Iron enrichment allocated at the corrosion front. Si and Mn were not observed there. ( $\mathrm{Cu}, \mathrm{Ni}$ and $\mathrm{Pt}$ are related to experimental artefacts.)

of the dark area can barely be recognized in Fe mapping in Fig. 6a (partially indicated by the white line) when the immersion and addition of the ferrofluid were performed in the absence of the external magnet since the magnetization of dark zones is very low. In contrast, in Fig. $6 \mathrm{~b}$ when electrolyte exposure and addition of the ferrofluid to the droplet were performed on a sample positioned on the neodymium-ironboron magnet the Bitter decoration method was more efficient. The arising dark areas show magnetic-force-related interaction because the magnetite nanoparticles of the ferrofluid clearly reproduce the shape of the dark area and align themselves around it (while the external magnet serves as a trigger for the weak magnetic field of the dark areas due to induced magnetization). Note that in Fig. 6b the ferrofluid is mostly assembled around the dark zones and weaker in the middle, suggesting that there is a higher content of Fe-rich phases concentrated at the periphery of the corrosion front of the dark area.

Certain morphological features, like the geometrical shape of the dark area in Fig. 6a, can be recognized at the top right corner, which indicates that both magnetic and capillary effects could attract magnetic nanoparticles to the black area of the sample that was not in contact with the magnet. A comparison with Fig. 6b suggests that with the magnet the pattern formation is dominated by the magnetic-field-induced interaction.

The observed magnetic field related effect can also be validated on samples used for the dark area simulation via 

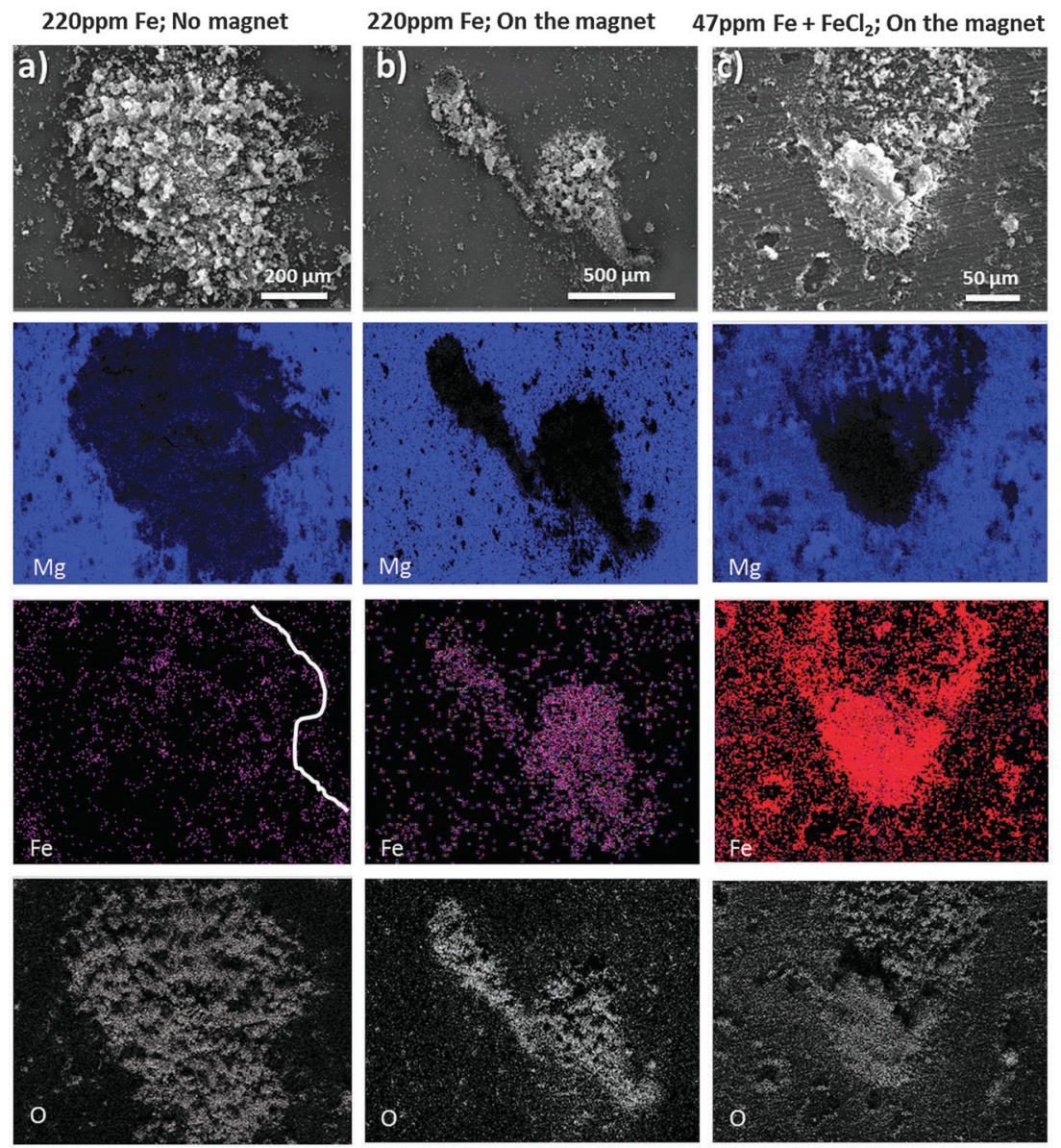

Fig. 6 SEM-EDS elemental mapping of the Mg surface (containing either $220 \mathrm{ppm} \mathrm{Fe} \mathrm{(a)} \mathrm{and} \mathrm{(b)} \mathrm{or} 47 \mathrm{ppm} \mathrm{Fe} \mathrm{(c)} \mathrm{after} \mathrm{short} \mathrm{exposure} \mathrm{to} 0.5 \% \mathrm{NaCl}$ and subsequently added ferrofluid). Additionally, the sample in (c) was polarized in $0.5 \% \mathrm{NaCl}$ containing $0.05 \mathrm{M} \mathrm{FeCl}_{2}$ before positioning on the magnet and adding the ferrofluid.

iron salt treatments. Even though there is a higher amount of iron deposited on the entire surface, there is a much stronger magnetic field at the dark area revealed by the enrichment and alignment of ferrofluid as shown in Fig. 6c. Note that in these experiments, the external magnet only served as an amplifier/ trigger, increasing the weak magnetic field of the black areas. If there does not present ferromagnetic material at the dark areas, the external magnet would not have anything to magnetize and no specific interaction of the dark area with the ferrofluid would occur. Moreover, no alignment of the ferrofluid was observed at the non-corroded surface away from the corroded areas.

The specimen which was corroded without the magnet (Fig. 7a) does not show the pattern formation due to low magnetization. In contrast the specimen, which was corroded on the magnet in (Fig. 7b), clearly shows that the formed black area interacts by magnetic forces because the magnetite nanoparticles of the ferrofluid are aligned in recognizable branches/pattern according to Bitter around the dark area. Note that this pattern could not have been formed exclusively by the magnetic field of the underlying magnet. If this would be the case, the ferrofluid enriched and aligned in the bottom right corner of Fig. $7 \mathrm{~b}$ should not remain on its position, but would move to the strongest magnetic field located lower on the sample and indicated by the vertical line in Fig. $7 \mathrm{~d}$. It is assumed that the underlying magnet acts as a trigger for the existing weak magnetic field. Due to its magnetization effect the interaction of Fe-rich dark areas with the ferrofluid was amplified. Also note that the Bitter-like patterns of the ferrofluid are not observed at long distances to the black area. Their aligned agglomerations are selectively found closely around the iron-rich dark areas.

The validation of this behaviour is shown in Fig. 7c. It was observed that similar pattern formation occurs in the same way for the iron deposition simulation case applying $\mathrm{FeCl}_{2}$ treatment with subsequent sufficient cathodic polarization here $(-1.2 \mathrm{~V} v s$. OCP $)$ in order to enable Fe re-deposition. All results clearly indicate the magnetic effect of dark areas and the existence of ferromagnetic material in dark areas, formed on corroding bare magnesium.

\subsection{In situ phase formation aspects}

GIXRD diffraction patterns are measured in situ, directly during the growth of the dark areas. The results in Fig. 8a show the expected strong $\mathrm{Mg}(\mathrm{OH})_{2}$ signal. The shape of the hydroxide 

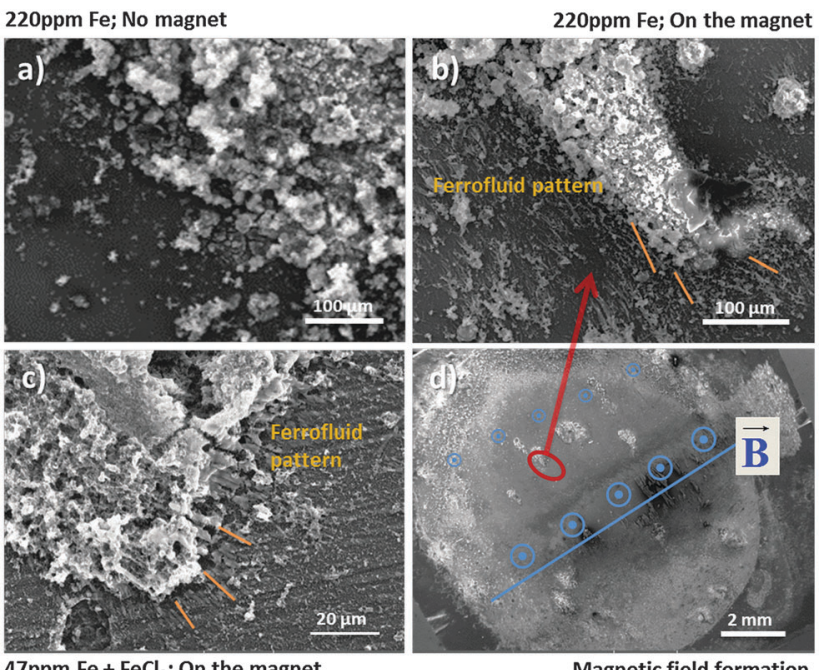

$47 p p m ~ F e+\mathrm{FeCl}_{2} ;$ On the magnet

Magnetic field formation

Fig. 7 Corrosion forefront (a) without magnetic structures, (b) and (c) with pattern formation according to Bitter decoration revealing the selective alignment of ferrofluid (marked by lines) around the black area formed under different conditions, and (d) magnetic field structure.

peaks is broadened due to crystal size effects (nanocrystallinity). In order to get the information of Fe rich phases the pattern has to be analyzed carefully.

Besides the expected $\alpha-\mathrm{Mg}$ and hydroxide pattern, weak signals in the background occur, which can be related to iron-rich phases. Due to the phase formation conditions which lead to a very thin (nanocrystalline) film and due to the low concentration of $\mathrm{Fe}$, only weak and broadened signals occur. Fig. $8 \mathrm{~b}$ explicitly shows a signal which is related to $\mathrm{Fe}(\mathrm{OH})_{2}$ at $2 \theta=31.8^{\circ}$. Furthermore, there are indications for lepidocrocite $(\gamma-\mathrm{FeOOH})$ formation at $2 \theta=27.5^{\circ}$. Other phases like magnetite $\left(\mathrm{Fe}_{3} \mathrm{O}_{4}\right)$, hematite $\left(\mathrm{Fe}_{2} \mathrm{O}_{3}\right)$, or goethite $(\alpha-\mathrm{FeOOH})$ cannot be assigned without doubts due to the peak overlap and the detection limit. The peak at $2 \theta=45^{\circ}$ raises questions since it fits to ferrite $(\alpha-\mathrm{Fe})\left[(011)=44.68^{\circ} ;(002)=65.03^{\circ}\right]$ and aluminum $($ sample holder $)\left[(111)=38.47^{\circ} ;(200)=44.74^{\circ} ;(220)=65.13^{\circ}\right]$. Aluminum cannot be excluded since the strongest reference peak at $2 \theta=38.47^{\circ}$ is overlapped by the $\mathrm{Mg}(\mathrm{OH})_{2}$ signal.

The observation that the strongest iron-related signal occurs at $0.9^{\circ}$ incident beam angle points out that iron-rich phases are located below magnesium hydroxide. This fits very well not only to recent research results in Section 3.4 based on the ferrofluid tests, but also to the studies of Curioni $e$ e $a .^{32}$ and Yang et al. ${ }^{39}$

\section{Discussion - mechanistic understanding of hydrogen generation}

\subsection{Implementation of the re-deposition mechanism}

During the corrosion of bare $\mathrm{Mg}$, containing a sufficient content of impurities like iron-rich particles, the introduced phenomena occur. Immersion into an aggressive/corrosive environment for a critical period of time changes the surface morphology due to anodic dissolution, release of impurities and the increase of the dark area fraction which is cathodically active (as shown in previously published studies ${ }^{17,23,24}$ and indicated in Fig. 9). The contribution of reactions at dark areas to the global hydrogen evolution rate becomes stronger with progressing corrosion. This is related to uncovered impurity surfaces and the increase of active film area as shown by other authors ${ }^{16}$ and stated by Yang $e t ~ a l .{ }^{39}$ The evolving dark surface area acts as the cathode. ${ }^{16,17,24,33}$ After coverage of the whole surface by the dark regions, the impact of the cathodically active dark film becomes dominant and the relative cathodic current contribution of the single impurities decreases. The results presented here explain the formation and the growth mechanism of dark areas. There is experimental evidence that the increase of the cathodic area is related to the re-deposition of dissolved iron species at the $\mathrm{Mg}$ surface.

The potential electrodeposition of Fe from alkaline electrolytes on different metallic substrates (Au, Ni) was already demonstrated by Yuan et al., ${ }^{65,66}$ Allanore et al. ${ }^{51,52,67}$ Flis-Kabulska et al., ${ }^{49,68}$ and Fray. ${ }^{69}$ According to Allanore et al. ${ }^{52}$ the re-deposition can also occur from solutions containing hematite particles.

A similar process is suggested by Flis-Kabulska et al. ${ }^{49,68}$ for enhanced electrocatalytic activity and reactivation of electrodes during electrolysis (with iron cathodes). They state that metallic reactive pure iron ("in statu nascendi") is deposited after the reduction of $\mathrm{Fe}(\mathrm{OH})_{4}{ }^{2-}$ at the site where hydrogen gas bubbles are formed, which fits to reactions shown by Le et al. and Armstrong et al. ${ }^{43,44}$ In another work ${ }^{70}$ they also show exactly the same slope for the pseudo-Tafel line of the hydrogen formation of $170 \mathrm{mV} \mathrm{dec}{ }^{-1}$ on active iron films as measured a)

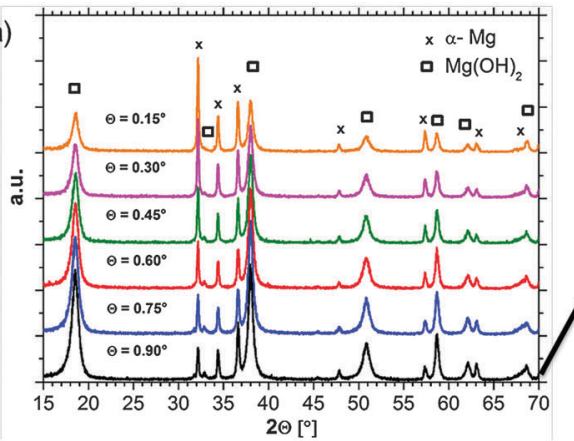

b)

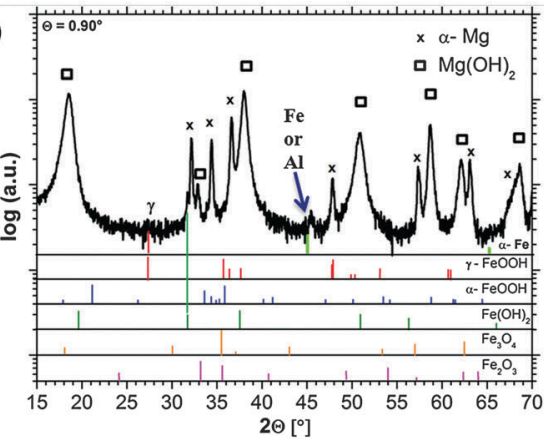

Fig. 8 (a) GIXRD pattern (measured in situ) after the formation of the dark area on $\mathrm{Mg}-65 \mathrm{ppm} \mathrm{Fe}$ in $0.5 \% \mathrm{NaCl}$ solution showing the growth of $\mathrm{Mg}(\mathrm{OH})_{2}$. (b) GIXRD diffraction patterns measured at an incident angle of $0.90^{\circ}$ (logarithmic scale) including the indication of probable phases. 


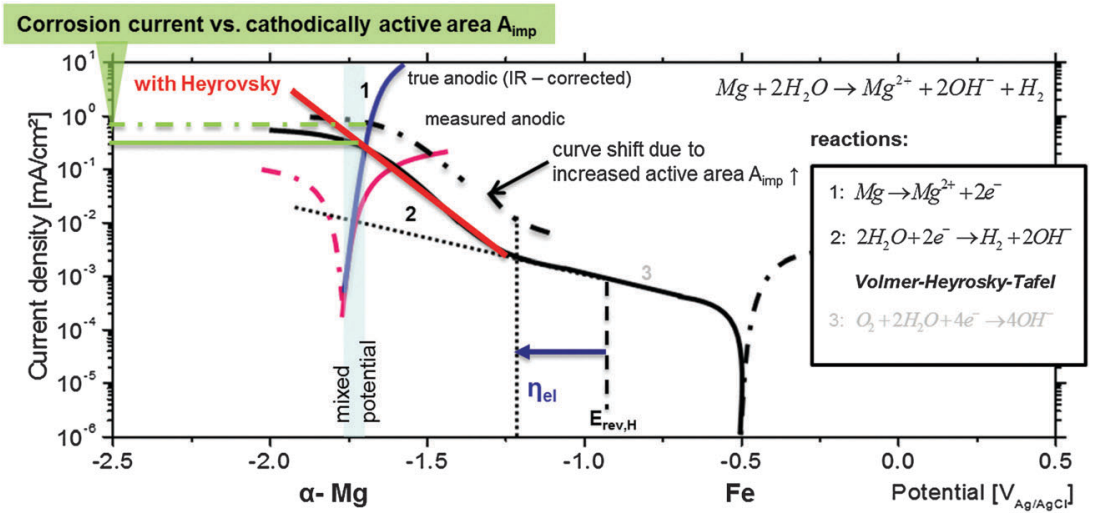

Fig. 9 Applied mixed potential theory, corrosion current density as a result of occurring reactions, the overpotential $\eta_{\mathrm{el}} V s$. $E_{\text {rev, } \mathrm{H}}$, the amount of cathodically active area $A_{i m p}$, and its relation to single polarization curves. The RHE potential is indicated as well.

in Fig. 10 in this paper. Possible reduction reactions can be found in the study of Misawa $e t a l^{71}$ or Stratmann et al. ${ }^{72}$ Thus, one can also expect that similar iron deposition processes can occur at the $\mathrm{Mg}$ surface during corrosion. In the case of magnesium corrosion, the iron source is the impurities, iron particles or iron rich intermetallics which are normally cathodically protected. However, during the corrosion process they lose electrical contact with $\mathrm{Mg}$, as shown by Taheri et al. ${ }^{16}$ and thus, start to dissolve via a self-corrosion mechanism rather rapidly. Dissolved iron can be reduced, and as a result very thin metallic iron layers or patches are re-deposited close to the hydroxide layer. This film is sufficient to force the cathodic behavior as proposed and indicated previously in Fig. 1 .

It has to be kept in mind that the dark appearance is also partially caused by the ongoing roughening effect which has to be considered as well. Based on the literature and experimental results presented in this paper, the process for dark area formation and at least the reason for the negative difference effect are proposed as follows:

(I) Initial cathodic process on Fe rich particles and anodic dissolution of Mg.

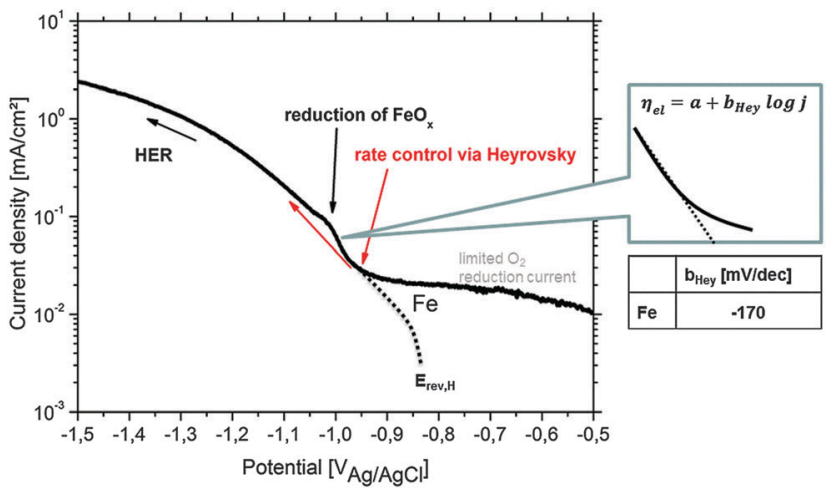

Fig. 10 Cathodic polarization curve on Fe in 90\% deaerated alkaline $0.5 \mathrm{wt} \% \mathrm{NaCl}$ solution $(\mathrm{pH}=10.5)$ simulating the conditions during $\mathrm{Mg}$ corrosion. The pseudo-Tafel slope $b_{\text {Hey }}$ in the Heyrovsky range follows the relation $2 \times 2.303 R T / F \leq b_{\mathrm{Hey}} \leq 3 \times 2.303 R T / F{ }^{83} E_{\mathrm{rev}, \mathrm{H}}$ and the (virtual) hydrogen reduction related curve are adapted from the study of Chialvo et al. ${ }^{78}$ Contribution to the current due to iron oxide reduction is labeled.
(II) Detachment of iron particles from the metallic substrate by undermining or hydrogen bubbles as proven in ref. 16, 39 and 40 .

(III) Chemical dissolution of detached iron-rich particles with the formation of $\mathrm{Fe}$ (II), $\mathrm{Fe}$ (III) or $\alpha-\mathrm{Fe}_{2} \mathrm{O}_{3}$ compounds (similar to ref. 39)

(IV) Chemical reduction (e.g. by adsorbed atomic hydrogen) of dissolved iron species to metallic Fe according to ref. 43, 44, and 49 (probably close to bubbles in combination with localized $\mathrm{pH}$ increase)

(V) Electrochemical reduction of Fe species (similar to processes on other substrates $^{51,52,67}$ )

(VI) Deposition of thin metallic Fe film or patches mainly at the moving corrosion forefront due to the most suitable conditions combined with $\mathrm{H}_{2}$ generation

(VII) Accelerated HER on the freshly deposited iron due to the increased reactivity of pure metal ("in statu nascendi") according to the Heyrovsky pathway as explained in Section 4.2

A similar re-deposition mechanism is also proven for S-phase $\left(\mathrm{Al}_{2} \mathrm{MgCu}\right)$ containing aluminum alloys by Buchheit et $a l .{ }^{73}$ and later by Yasakau et al. ${ }^{74}$ and El Warraky et al. ${ }^{75}$ Due to the fast dissolution of $\mathrm{Mg}$ and then $\mathrm{Al}$, the S-phase becomes porous and enriched with copper. The detachment of copper nanoparticles and their dissolution followed by re-deposition on the aluminium matrix covered with $\mathrm{Al}_{2} \mathrm{O}_{3}$ in the vicinity of the de-alloyed S-phase enlarge the cathode and propel further corrosion. In ref. 75 it was shown that a concentration of only $2 \mathrm{ppm} \mathrm{CuCl}_{2}$ diluted in $0.5 \mathrm{M} \mathrm{NaCl}$ is sufficient to cover the entire surface of $\mathrm{Al}$ of their test samples with $\mathrm{Cu}$. This is a clear hint that this kind of dissolution and re-deposition mechanism demonstrated for $\mathrm{Al}-\mathrm{Cu}$ might be also feasible for $\mathrm{Mg}-\mathrm{Fe}$. The related NDE on aluminum is weaker since local cathodic polarization on the active surface area is not as high as for magnesium. In the appendix an approximation of critical $\mathrm{Fe}$ content for the $\mathrm{Mg}-\mathrm{Fe}$ system is given. Briefly, around $20 \mathrm{Fe}$ intermetallic inclusions (fully dissolved) with an average diameter of $1 \mu \mathrm{m}$ are theoretically enough to cover $1 \mathrm{~cm}^{2}$ of the $\mathrm{Mg}$ surface with a continuous Fe monolayer.

\subsection{Heyrovsky pathway}

The achieved results evidence that Fe impurities dissolved in the $\mathrm{Mg}$ matrix can be re-deposited on the surface, forming a 
thin iron-based film which acts as an effective cathode for the HER. However the observed high rate of HER, especially at slightly anodic polarizations, cannot be justified only by the increase of cathodic area if one assumes that hydrogen evolution occurs via the commonly accepted Volmer-Tafel mechanism.

Generally, for high cathodic polarizations of pure samples of the metals found as noble impurities in $\mathrm{Mg}$, which e.g. correspond to low anodic polarization of the Mg-matrix, the rate determining step for HER differs. The rate determining reaction at low cathodic polarization vs. OCP of e.g. pure Fe is typically diffusion limited $\mathrm{O}_{2}$ reduction. Cathodic polarization of e.g. Fe, $\mathrm{Ni}$ and $\mathrm{Cu}$ above the reverse hydrogen potential $E_{\mathrm{rev}, \mathrm{H}}$ induces the HER. The rate determining step for the HER is a Volmer-type reaction of electrochemical adsorption. The rate of this process increases with continuing polarization. Then the chemical recombination of the intermediate state adsorbed hydrogen atoms followed by the desorption of hydrogen molecules controls the kinetics according to the Tafel step. However, continuing to even higher cathodic polarization activates the electrochemical desorption of hydrogen according to the Heyrovsky mechanism, ${ }^{76}$ especially on $3 \mathrm{~d}$ transition metals. Vilekar et $a .^{77}$ performed a very fundamental study on the kinetics of hydrogen reactions on Pt under alkaline conditions, showing the Heyrovsky step to be rate-determining for cathodic polarization more than $-0.2 \mathrm{~V} v s$. $E_{\mathrm{rev}, \mathrm{H}}(\mathrm{RHE})$. Chialvo et al. ${ }^{78}$ studied the HER on iron in $2 \mathrm{M} \mathrm{NaOH}$ and explained the kinetics by a three step Volmer-Heyrovsky-Tafel mechanism. They showed that the apparent activation energy they measured corresponds to the Volmer or Heyrovsky step. Another investigation by Qian et al. ${ }^{79}$ on iron in $0.2 \mathrm{M} \mathrm{NaOH}$ showed the occurrence of control via the Heyrovsky pathway as well. Therefore it is reasonable to suggest that at high cathodic polarizations in alkaline electrolytes the HER on iron-containing zones on $\mathrm{Mg}$ occurs via the Heyrovsky mechanism. As a result a much higher HER rate can be observed than in the case of the Tafel step.

The potential (marked as $\eta_{\mathrm{el}}$ in Fig. 9) at which the Heyrovsky path takes over the rate (current) control is specific for each metal under certain conditions and depends on the metalhydrogen $(\mathrm{M}-\mathrm{H})$ bond energy. The domination of the VolmerHeyrovsky pathway was shown and clearly validated for iron even at moderate overpotentials. ${ }^{79}$ For nickel the rate control depends on the position of the cathodic branch. It was shown by Krstajic et al. ${ }^{80}$ that at certain cathodic overpotentials the Heyrovsky reaction is rate-determining as well. Further investigations on copper ${ }^{81}$ have also shown the same mechanism.

Thus, it is reasonable to assume that, at the corrosion (mixed) potential of $\mathrm{Mg}$-based substrates, the noble ( $\mathrm{Fe}, \mathrm{Cu}$, and $\mathrm{Ni}$ ) inclusions can be highly cathodically polarized and might be exposed to conditions when the Heyrovsky step becomes ratedetermining as shown in Fig. 9. Crossing the Heyrovsky branch of the impurity elements (here $\mathrm{Fe}$ ) with the corrected anodic branch of $\alpha$-Mg delivers the corrosion rate as marked in Fig. 9.

The upward shift of the cathodic branch is related to the

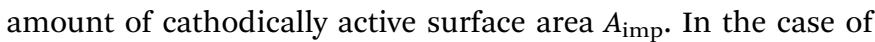
dark area formation $A_{\text {imp }}$ increases, and as a result the final corrosion current becomes higher. The explanation of Fig. 9 contributes to the interpretation of measured polarization curves of $\mathrm{Mg}$ with different amounts of impurities (here $\mathrm{Fe}$ ). The enhanced cathodic activity (incl. HER and IR-drop), the shift of measured OCP and the corrosion rate are the physicochemical consequences of previously explained behaviour.

The HER kinetics itself strongly depends on the kind of impurity, alloying element and/or compound involved in the corrosion process. In order to validate the Heyrovsky contribution aspect, the cathodic polarization of bulk specimens of $\mathrm{Fe}$ as the most common impurity element was performed under corrosion conditions comparable to those occurring on $\mathrm{Mg}$ alloys (alkaline $\mathrm{pH})$ as discussed in Section 3.1 and shown in Fig. 10. Very important information is received at approx. $-1.0 \mathrm{~V}_{\mathrm{Ag} / \mathrm{AgCl}}$ during iron polarization. A peak occurs which is related to the reduction of iron oxides to metallic iron. ${ }^{43,44,52,68}$ The current density gets contribution due to newly formed metallic Fe. Heyrovsky reaction at this point arises on the impurities and on the re-deposited iron film (not on iron oxides).

The presented experimental results in Fig. 10 agree well with the literature ${ }^{82}$ and also validate the "pseudo-Tafel" description of Heyrovsky reactions. In particular the measured slopes $b_{\text {Hey }}$ clearly fit to the theory where $b_{\text {Hey }}$ follows the relation $2 \times 2.303 R T / F \leq b_{\text {Hey }} \leq 3 \times 2.303 R T / F .{ }^{83}$ More details on the scientific background, about the switch to the Heyrovsky pathway, can be found in the work of Fang et al. or Vilekar et al. ${ }^{77,84}$

In the case of alkaline conditions observed at a corroding $\mathrm{Mg}$ surface this pathway can be represented in the following way:

$$
\mathrm{M}+\mathrm{H}_{2} \mathrm{O}+\mathrm{e}^{-} \rightarrow \mathrm{M}-\mathrm{H}_{\mathrm{ad}}+\mathrm{OH}^{-}
$$

(Volmer - V - electrochemical adsorption of hydrogen)

$$
2 \mathrm{H}_{\mathrm{ad}} \rightarrow \mathrm{H}_{2} \quad \text { (Tafel }-\mathrm{T}-\text { chemical desorption of hydrogen) }
$$

$$
\mathrm{H}_{\mathrm{ad}}+\mathrm{H}_{2} \mathrm{O}+\mathrm{e}^{-} \rightarrow \mathrm{H}_{2}+\mathrm{OH}^{-}
$$

(Heyrovsky - H - electrochemical desorption of hydrogen)

The three possible reaction steps are schematically illustrated in Fig. 11, which also illustrates the main idea of the mechanism behind the negative difference effect. Water molecules are discharged according to Volmer on the metal $M$ followed by a subsequently Tafel or/and Heyrovsky reaction (V-T, V-H or $\mathrm{V}-\mathrm{TH}$ pathway). The kinetics of the whole process depend on the cathodic overpotential, the Gibbs energy of adsorbed hydrogen $\mathrm{H}_{\mathrm{ad}}$ at the top layer and the hydrogen surface coverage. ${ }^{79}$ If one compares previously shown experimental results, especially from TEM and XRD, on magnesium with the theoretical background of Heyrovsky reactions, the logical conclusion is that electrochemical desorption according to the Heyrovsky pathway drives hydrogen generation during $\mathrm{Mg}$ corrosion in the presence of $\mathrm{Fe}, \mathrm{Ni}$, and $\mathrm{Cu}$ impurities.

Thus, the additive combination of two effects, namely the fast Heyrovsky HER with continuously enhanced surface fraction of the cathodic area especially due to the iron re-deposition, ensures high hydrogen evolution at the $\mathrm{Mg}$ surface subjected to 
a) cross sectional view:

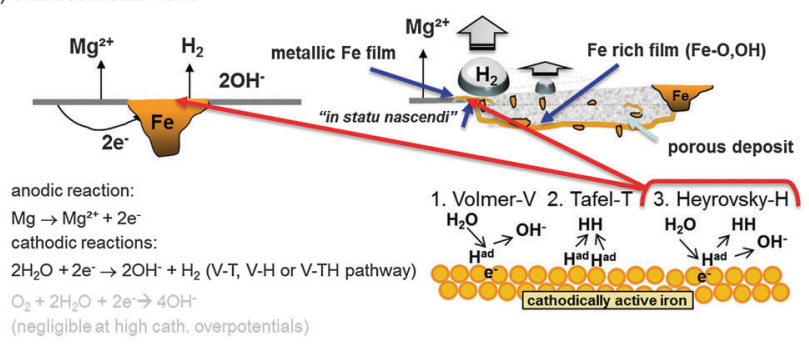

b) top view:
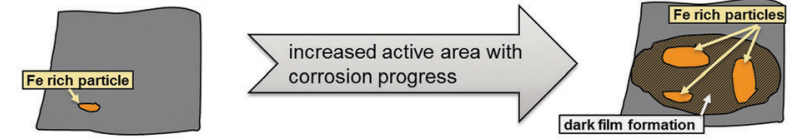

Fig. 11 Schematic representation of a typical Mg system with Fe rich impurities showing the initial increase of cathodic active (dark) area based on findings of Curioni et al. ${ }^{32}$ (a) shows a cross-sectional view and involved anodic and cathodic reactions especially on the redeposited Fe film. (b) Anodic dissolution of $\mathrm{Mg}$ results in the increase of active area as shown by Taheri et al. ${ }^{85}$ and subsequent film formation based on the mechanism proposed by Flis-Kabulska et al. ${ }^{49}$

relatively low anodic polarization. In addition the very low polarization resistance of magnesium contributes to this mechanism, since it prevents the occurrence of low hydrogen overpotentials at cathodic areas where the rate control should change between the Heyrovsky reaction and the Tafel reaction $(\mathrm{V}-\mathrm{T} \rightarrow \mathrm{V}-\mathrm{TH} \rightarrow \mathrm{V}-\mathrm{H})$. As a result, according to the mixed potential theory, the global anodic net-polarization point can only slightly shift towards more positive values. Despite the strong dependency of the local mixed potential on the surface state and the amount of cathodically active area, on the amount and condition of alpha magnesium, and on the electrolyte composition, true cathodic overpotentials at the impurities, which induce Tafel reaction control of hydrogen generation or even control by oxygen reduction reaction, cannot occur.

At this point oxygen reduction gives main contribution to the oxidation of iron species. Thus, oxygen plays an important role in $\mathrm{Mg}$ corrosion, which is in contrast to common assumptions. Minor contribution can be considered for hydrogen evolution by the Tafel reaction at the $\alpha-\mathrm{Mg}$ surface because of the very low hydrogen evolution exchange current at the $\mathrm{Mg}$ surface.

A theoretical contradiction to the approach occurs at higher anodic polarization where HER still increases. In that situation the contribution of Heyrovsky reactions should theoretically decrease since cathodic overpotential should decrease, but it does not. Explanation of this discrepancy requires the discussion of process kinetics. King ${ }^{86}$ and Frankel's ${ }^{7}$ work studied the IR-drop through the electrolyte. The strength of such a drop on active electrodes due to gas bubbles has been investigated in the literature ${ }^{87,88}$ and can locally exceed hundreds of $\mathrm{mV}$. If one considers even higher anodic polarization an increased gas evolution is observed. Under these conditions a truly anodic polarization which hinders hydrogen evolution cannot be reached. The IR-drop increases fast in correlation with the current, since the anodic reaction is kinetically fast, based on the very low polarization resistance of magnesium. As a result, the developing mixed potential is always very close to the OCP of the less noble phase $(\alpha-\mathrm{Mg})$ and the Heyrovsky reaction remains active. Thus, the $\mathrm{V}-\mathrm{H}$ pathway cannot be switched off by the increase of applied positive potentials simply because magnesium is not anodically polarizable.

The remaining question of the contribution to cathodic reactions by the $\alpha-\mathrm{Mg}$ surface can be partially answered as well. As explained within the introduction, compared to transition metals such as $\mathrm{Fe}$ or $\mathrm{Ni}$, which are known as efficient electrodes for hydrogen production, magnesium does not exhibit d-orbitals which can interact with the hydrogen anti-bonding orbital and thus facilitate the dissociation of molecular hydrogen. ${ }^{89}$ The preferred reaction pathway is $\mathrm{V}-\mathrm{T}$. Thus, pure $\alpha-\mathrm{Mg}$ surfaces do not drive hydrogen dissociation on the $\mathrm{V}-\mathrm{H}$ pathway ${ }^{30}$ and as a result, just slightly contribute to the strong hydrogen gas evolution, which is typically measured for impurities containing magnesium during corrosion. At low impurity levels the dopant effect $^{31}$ might work. Hence, the water reduction during cathodic polarization is even more efficient on impurities and dark areas, which corresponds to the literature findings. ${ }^{16,22,26}$

\section{Conclusions}

The present work contributes to the better understanding of the corrosion mechanisms of $\mathrm{Mg}$ substrates containing iron impurities. For the first time the enhanced hydrogen evolution is correlated with the possible electrochemical re-deposition of a thin iron (patch) film on the magnesium surface. Re-deposition accelerates HER and becomes the determining process after an initial period. The assumed formation of re-deposited Fe was confirmed by the results of in situ GIXRD and application of ferrofluids according to the Bitter decoration method.

Additionally, the Heyrovsky mechanism of HER on the redeposited iron surface is discussed as a potential reason for the enhanced rate of hydrogen evolution even at high $\mathrm{pH}$ values.

Based on the progress being achieved in related research and by adding the new aspect of this study, the following conclusions can be drawn:

(1) Dark film formation $\left(\mathrm{Mg}(\mathrm{OH})_{2}+\right.$ Fe rich film) is related to the deposition of thin metallic iron layers especially at the moving corrosion front as a result of impurity self-corrosion and subsequent reduction of iron species at higher cathodic polarizations of approx. $-1 \mathrm{~V}_{\mathrm{Ag} / \mathrm{AgCl}}$ (in combination with the generation of highly reactive atomic hydrogen) and subsequent corrosion product deposition (magnesium hydroxide precipitation).

(2) SEM-EDS analysis of the distribution of ferrofluid around the black areas formed on the $\mathrm{Mg}$ sample placed on the magnet shows that the dark areas influence the local magnetic field which can be explained by their enrichment with $\mathrm{Fe}$ and/or iron oxides/hydroxides, which was also shown by TEM studies. The results of GIXRD indicate the formation of $\mathrm{Fe}(\mathrm{OH})_{2}$ and $\gamma$-FeOOH in the dark areas.

(3) As corrosion progresses, re-deposited Fe films "in-statu nascend $i$ " at the corrosion forefront drive the cathodic current and become the most active $\mathrm{H}_{2}$ generator. 
(4) The initial HER and its kinetics are related to the amount, and the effective surface fraction of metallic impurities and/or intermetallics, and their respective electrochemical hydrogen desorption kinetics according to the Heyrovsky mechanism. The electrochemical desorption process has much faster kinetics than the chemical desorption described by the Tafel mechanism.

(5) The re-deposition mechanism combined with electrochemical desorption kinetics according to the Heyrovsky pathway is an adequate candidate for the explanation of observed phenomena generally known as the negative difference effect - NDE.

(6) Restricting the Fe re-deposition offers the ability to create new strategies for corrosion control of Fe-containing $\mathrm{Mg}$ substrates.

\section{Appendix}

The calculation of the number of deposited Fe monolayers "in statu nascendi", formed during the growth of the dark area

$100 \mathrm{ml}$ of $0.5 \mathrm{M} \mathrm{FeCl}_{2}\left(\mathrm{FeCl}_{2} \cdot 4 \mathrm{H}_{2} \mathrm{O}\left(198.83 \mathrm{~g} \mathrm{~mol}^{-1}\right)\right)$ was used for the tests. A rough approximation can be carried out:

- A total of $\sim 2.8 \mathrm{~g}$ of Fe was dissolved which corresponds to $\sim 3 \times 10^{22}$ atoms

- The size of the immersed $\mathrm{Mg}$ sample was approx. $3 \mathrm{~cm}^{2}$. Upon considering the increase due to surface roughness, we can simply assume that about $10 \mathrm{~cm}^{2}$ are covered.

- By taking the "area" of one iron atom in a bcc structure $\left(a=0.287 \mathrm{~nm}\right.$ ) to be $8.24 \times 10^{-16} \mathrm{~cm}^{2}$ we get a number of atoms of $8.24 \times 10^{17}$, which is theoretically required to cover the sample with a monolayer

- According to $3 \times 10^{22} / 8.24 \times 10^{17}=3.6 \times 10^{4}$ Fe monolayers could be deposited on the $\mathrm{Mg}$ surface.

For the used test samples (in a worse scenario of low deposition rate) we simply assume that one of the thousand atoms is re-deposited. As a result, the surface still can be fully covered (theoretically) by an active film. And in reality the surface composition is a mixture of iron, $\mathrm{Mg}$ and $\mathrm{Mg}(\mathrm{OH})_{2}$.

In the case of impurities this approximation can give the contribution of $\mathrm{Fe}$ particles of e.g. $1 \mu \mathrm{m}$ diameter. Such a particle has a weight of about $5 \mathrm{ng}$ and is constituted of $5 \times 10^{13}$ atoms. This leads to a surface coverage of $\sim 0.05 \mathrm{~cm}^{2}$ per particle. In other words, 20 of such iron particles are sufficient to cover $1 \mathrm{~cm}^{2}$ with active iron. An experimental showcase can be found in the study of Samaniego et l. $^{21}$

\section{Acknowledgements}

Dr Höche would like to thank Dr W. Dietzel for input and discussions, Dr A. Schwarz from University of Hamburg for assisting the ferrofluid application, Dr Marc Willinger and Michael Scherzer from the Department of Inorganic Chemistry at Fritz Haber Institute of the Max Planck Society for their contribution to the diffraction experiments and Eng. U. Burmester for setting up the experimental equipment. Dr Lamaka acknowledges the financial support of Alexander von Humboldt Foundation via the Experienced Researcher Grant.

\section{References}

1 G. Williams, N. Birbilis and H. N. McMurray, Electrochem. Commun., 2013, 36, 1-5.

2 A. Atrens and W. Dietzel, Adv. Eng. Mater., 2007, 9, 292-297. 3 J. A. Boyer, The Corrosion of Magnesium and of the Magnesium Aluminum Alloys Containing Manganese, Report 248, United States National Advisory Committee for Aeronautics, Washington, 1926.

4 R. Tunold, H. Holtan, M.-B. H. Berge, A. Lasson and R. Steen-Hansen, Corros. Sci., 1977, 17, 353-365.

5 W. J. James, M. E. Straumanis, B. K. Bhatia and J. W. Johnson, J. Electrochem. Soc., 1963, 110, 1117-1120.

6 J. L. Robinson and P. F. King, J. Electrochem. Soc., 1961, 108, 36-41.

7 G. S. Frankel, A. Samaniego and N. Birbilis, Corros. Sci., 2013, 70, 104-111.

8 N. T. Kirkland, G. Williams and N. Birbilis, Corros. Sci., 2013, 77, 407-409.

9 Z. Shi and A. Atrens, Corros. Sci., 2013, 77, 403-406.

10 M. E. Straumanis and Y. N. Wang, J. Electrochem. Soc., 1955, 102, 304-310.

11 M. Garreau and P. L. Bonora, J. Appl. Electrochem., 1977, 7, 197-209.

12 D. M. Dražić and J. P. Popić, J. Appl. Electrochem., 1999, 29, 43-50.

13 L. Rossrucker, K. J. J. Mayrhofer, G. S. Frankel and N. Birbilis, J. Electrochem. Soc., 2014, 161, C115-C119.

14 N. Birbilis, G. Williams, K. Gusieva, A. Samaniego, M. A. Gibson and H. N. McMurray, Electrochem. Commun., 2013, 34, 295-298.

15 N. T. Kirkland, G. Williams and N. Birbilis, Corros. Sci., 2012, 65, 5-9.

16 M. Taheri, J. R. Kish, N. Birbilis, M. Danaie, E. A. McNally and J. R. McDermid, Electrochim. Acta, 2014, 116, 396-403.

17 M. Curioni, Electrochim. Acta, 2014, 120, 284-292.

18 S. Bender, J. Göllner, A. Heyn and S. Schmigalla, Mater. Corros., 2012, 63, 707-712.

19 A. Atrens, G.-L. Song, F. Cao, Z. Shi and P. K. Bowen, J. Magnesium Alloys, 2013, 1, 177-200.

20 G. S. Frankel, S. Fajardo and B. M. Lynch, Faraday Discuss., 2015, 180, 11-33.

21 A. Samaniego, N. Birbilis, X. Xia and G. S. Frankel, Corrosion, 2015, 71, 224-233.

22 N. Birbilis, A. D. King, S. Thomas, G. S. Frankel and J. R. Scully, Electrochim. Acta, 2014, 132, 277-283.

23 S. Lebouil, O. Gharbi, P. Volovitch and K. Ogle, Corrosion, 2015, 71, 234-241.

24 S. Thomas, N. V. Medhekar, G. S. Frankel and N. Birbilis, Curr. Opin. Solid State Mater. Sci., 2015, 19, 85-94.

25 S. M. Nelson, A. C. D. Newman, T. E. Tomlinson and L. E. Sutton, Trans. Faraday Soc., 1959, 55, 2186-2202.

26 S. Fajardo and G. S. Frankel, Electrochim. Acta, 2015, 165, 255-267. 27 D. M. Bird, L. J. Clarke, M. C. Payne and I. Stich, Chem. Phys. Lett., 1993, 212, 518-524.

28 S. Trasatti, J. Electroanal. Chem., 1972, 39, 163-184.

29 J. K. Nørskov, A. Houmøller, P. K. Johansson and B. I. Lundqvist, Phys. Rev. Lett., 1981, 46, 257-260. 
30 T. Vegge, Phys. Rev. B: Condens. Matter Mater. Phys., 2004, 70, 035412.

31 M. Pozzo and D. Alfè, Int. J. Hydrogen Energy, 2009, 34, 1922-1930.

32 M. Curioni, F. Scenini, T. Monetta and F. Bellucci, Electrochim. Acta, 2015, 166, 372-384.

33 G. Williams, N. Birbilis and H. N. McMurray, Faraday Discuss., 2015, 180, 313-330.

34 M. P. Brady, G. Rother, L. M. Anovitz, K. C. Littrell, K. A. Unocic, H. H. Elsentriecy, G. L. Song, J. K. Thomson, N. C. Gallego and B. Davis, J. Electrochem. Soc., 2015, 162, C140-C149.

35 D. Höche, J. Electrochem. Soc., 2015, 162, C1-C11.

36 C. Deslouis, D. Festy, O. Gil, V. Maillot, S. Touzain and B. Tribollet, Electrochim. Acta, 2000, 45, 1837-1845.

37 L. Rossrucker, A. Samaniego, J. P. Grote, A. M. Mingers, C. A. Laska, N. Birbilis, G. S. Frankel and K. J. J. Mayrhofer, J. Electrochem. Soc., 2015, 162, C333-C339.

38 T. Cain, S. B. Madden, N. Birbilis and J. R. Scully, J. Electrochem. Soc., 2015, 162, C228-C237.

39 L. Yang, X. Zhou, M. Curioni, S. Pawar, H. Liu, Z. Fan, G. Scamans and G. Thompson, J. Electrochem. Soc., 2015, 162, C362-C368.

40 D. Lysne, S. Thomas, M. F. Hurley and N. Birbilis, J. Electrochem. Soc., 2015, 162, C396-C402.

41 S. H. Salleh, S. Thomas, J. A. Yuwono, K. Venkatesan and N. Birbilis, Electrochim. Acta, 2015, 161, 144-152.

42 K. S. Williams, J. P. Labukas, V. Rodriguez-Santiago and J. W. Andzelm, Corrosion, 2014, 71, 209-223.

43 H. H. Le and E. Ghali, J. Appl. Electrochem., 1993, 23, 72-77.

44 R. D. Armstrong and I. Baurhoo, J. Electroanal. Chem., 1972, 40, 325-338.

45 P. Dauphin-Ducharme and J. Mauzeroll, Anal. Chem., 2015, 87, 7499-7509.

46 F. Bitter, Phys. Rev., 1931, 38, 1903-1905.

47 M. Scherzer, PhD thesis, Fritz Haber Institut der Max Planck Gesellschaft, 2015.

48 M. Sipiczki, E. Kuzmann, Z. Homonnay, J. Megyeri, K. Kovács, I. Pálinkó and P. Sipos, Hyperfine Interact., 2013, 217, 145-149.

49 I. Flis-Kabulska, J. Flis, Y. Sun and T. Zakroczymski, Electrochim. Acta, 2015, 167, 61-68.

50 X. Zou, S. Gu, H. Cheng, X. Lu, Z. Zhou, C. Li and W. Ding, J. Electrochem. Soc., 2015, 162, D49-D55.

51 A. Allanore, H. Lavelaine, G. Valentin, J. P. Birat, P. Delcroix and F. Lapicque, Electrochim. Acta, 2010, 55, 4007-4013.

52 A. Allanore, H. Lavelaine, G. Valentin, J. P. Birat and F. Lapicque, J. Electrochem. Soc., 2007, 154, E187-E193.

53 B. Beverskog and I. Puigdomenech, Corros. Sci., 1996, 38, 2121-2135.

54 S. Hofmann, Surf. Interface Anal., 1986, 9, 3-20.

55 M. Descostes, F. Mercier, N. Thromat, C. Beaucaire and M. Gautier-Soyer, Appl. Surf. Sci., 2000, 165, 288-302.

56 M. C. Biesinger, B. P. Payne, A. P. Grosvenor, L. W. M. Lau, A. R. Gerson and R. S. C. Smart, Appl. Surf. Sci., 2011, 257, 2717-2730.

57 A. P. Grosvenor, B. A. Kobe, M. C. Biesinger and N. S. McIntyre, Surf. Interface Anal., 2004, 36, 1564-1574.

58 M. S. Mel'gunov, V. B. Fenelonov, E. A. Mel'gunova, A. F. Bedilo and K. J. Klabunde, J. Phys. Chem. B, 2003, 107, 2427-2434.
59 G. Baril and N. Pébère, Corros. Sci., 2001, 43, 471-484.

60 J. H. Nordlien, S. Ono, N. Masuko and K. Nisancioglu, J. Electrochem. Soc., 1995, 142, 3320-3322.

61 R. Zboril, M. Mashlan and D. Petridis, Chem. Mater., 2002, 14, 969-982.

62 B. J. Lemaire, P. Davidson, J. Ferré, J. P. Jamet, P. Panine, I. Dozov and J. P. Jolivet, Phys. Rev. Lett., 2002, 88, 125507.

63 O. Perales Perez, Y. Umetsu and H. Sasaki, Hydrometallurgy, 1998, 50, 223-242.

64 J. D. Bernal, D. R. Dasgupta and A. L. Mackay, Clay Miner. Bull., 1959, 4, 15.

65 B. Yuan and G. M. Haarberg, ECS Trans., 2009, 16, 31-37. 66 G. M. Haarberg and B. Yuan, ECS Trans., 2014, 58, 19-28.

67 A. Allanore, L. Yin and D. R. Sadoway, Nature, 2013, 497, 353-356.

68 I. Flis-Kabulska and J. Flis, Int. J. Hydrogen Energy, 2014, 39, 3597-3605.

69 D. Fray, Nature, 2013, 497, 324-325.

70 I. Flis-Kabulska, J. Flis and T. Zakroczymski, Electrochim. Acta, 2008, 53, 3094-3101.

71 T. Misawa, Corros. Sci., 1973, 13, 659-676.

72 M. Stratmann, K. Bohnenkamp and H. J. Engell, Corros. Sci., 1983, 23, 969-985.

73 R. G. Buchheit, R. P. Grant, P. F. Hlava, B. McKenzie and G. L. Zender, J. Electrochem. Soc., 1997, 144, 2621-2628.

74 K. A. Yasakau, M. L. Zheludkevich, S. V. Lamaka and M. G. S. Ferreira, J. Phys. Chem. B, 2006, 110, 5515-5528.

75 A. A. E. Warraky, A. M. El-Aziz and K. A. Soliman, AntiCorros. Methods Mater., 2007, 54, 155-162.

76 M. R. Gennero de Chialvo and A. C. Chialvo, Electrochim. Acta, 1998, 44, 841-851.

77 S. A. Vilekar, I. Fishtik and R. Datta, J. Electrochem. Soc., 2010, 157, B1040-B1050.

78 M. R. Gennero de Chialvo and A. C. Chialvo, Phys. Chem. Chem. Phys., 2001, 3, 3180-3184.

79 S. Y. Qian, B. E. Conway and G. Jerkiewicz, J. Chem. Soc., Faraday Trans., 1998, 94, 2945-2954.

80 N. Krstajić, M. Popović, B. Grgur, M. Vojnović and D. Šepa, J. Electroanal. Chem., 2001, 512, 16-26.

81 S. Sharifi-Asl and D. D. Macdonald, J. Electrochem. Soc., 2013, 160, H382-H391.

82 M. R. Gennero de Chialvo and A. C. Chialvo, Electrochem. Commun., 1999, 1, 379-382.

83 M. R. G. de Chialvo and A. C. Chialvo, J. Electroanal. Chem., 1994, 372, 209-223.

84 Y.-H. Fang, G.-F. Wei and Z.-P. Liu, J. Phys. Chem. C, 2013, 117, 7669-7680.

85 M. Taheri, R. C. Phillips, J. R. Kish and G. A. Botton, Corros. Sci., 2012, 59, 222-228.

86 A. D. King, N. Birbilis and J. R. Scully, Electrochim. Acta, 2014, 121, 394-406.

87 G. Kreysa and H. J. Külps, J. Electrochem. Soc., 1981, 128, 979-984.

88 D. Kiuchi, H. Matsushima, Y. Fukunaka and K. Kuribayashi, J. Electrochem. Soc., 2006, 153, E138-E143.

89 K.-F. Aguey-Zinsou and J.-R. Ares-Fernandez, Energy Environ. Sci., 2010, 3, 526-543. 